\title{
العلاقة بين الكفاءة المهنية لمعلم و رغبة التلاميذ في تعلم اللغة العربية بمهارة قراءة النص العبية بالمدرسة العالية المهاجرين موس رواس سومطرى الجنوبية
}

\begin{abstract}
${ }^{1}$ Yuniar, ${ }^{2}$ Atikah Marwa
Email: yuniar uin@,radenfatah.ac.id

1,2 جامعة رادين فتاح الإسلامية الحلكومية فالمبانج

ملخص: العلاقة بين الكفاءة المهنية لمعلم ورغبة التلاميذ في تعلم اللغة العربية بمهارة قراءة النص العربية بالمدرسة العالية المهاجرين موسي رواس سومطرى الجنوبية. هذا البحث سيبحث عن كيف الكفاءة المهنية لمعلم اللغة العربية وكيف رغبة التلاميذ في تعلم اللغة العربية وكيف مهارة قراءة النص العربية وكيف العلاقة بين الكفاءة المهنية لمعلم اللغة العربية ورغبة التلاميذ في تعلم اللغة العربية بمهارة قراءة النص العربية. فنتائج البحث هي

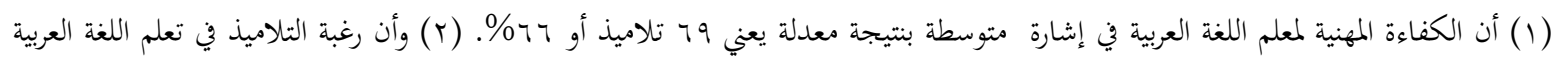

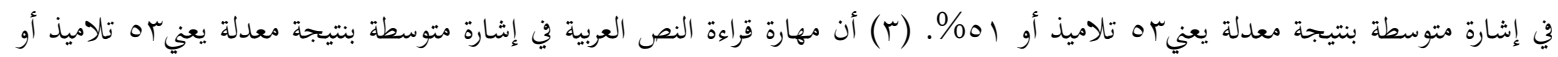
اهه\% ـ (ع) العلاقة بين الكفاءة المهنية لمعلم ورغبة التلاميذ بمهارة قراءة النص العربية بالمدرسة العالية المهاجرين موسي رواس قوية أو عالية بنتيجة

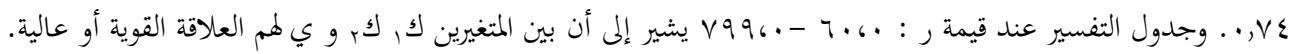

الكلمات الأساسية: الكفاءة المهنية، المعلم، رغبة التلاميذ

Abstrak: Kompetensi profesionalisme guru dan minat belajar bahasa Arab siswa dengan keterampilan membaca teks berbahasa Arab di MA Al Muhajirin Musi Rawas Sumatera Selatan. Hasil penelitian ini menyatakan bahwa (1) kompetensi profesionalisme guru bahasa Arab MA Al Muhajirin Musi Rawas sedang, dengan jumlah responden yang memilih sebanyak 69 siswa atau 66\%. (2) minat belajar bahasa Arab siswa MA Al Muhajirin sedang, dengan jumlah responden yang memilih sebanyak 53 siswa atau 51\%. (3) keterampilan membaca teks berbahasa Arab siswa sedang, dengan jumlah responden yang memilih sebanyak 53 siswa atau 51\%. (4) korelasi kompetensi profesionalisme guru bahasa Arab dan minat belajar siswa dengan keterampilan membaca teks berbahasa Arab di MA Al Muhajirin kuat atau tinggi dengan angka 0,74 dan $r=0,60-0,799$ menunjukkan hubungan $x_{1} x_{2}$ dan y memiliki hubungan yang kuat dan tinggi.
\end{abstract}

Kata kunci: Kompetensi profesional, guru, minat belajar

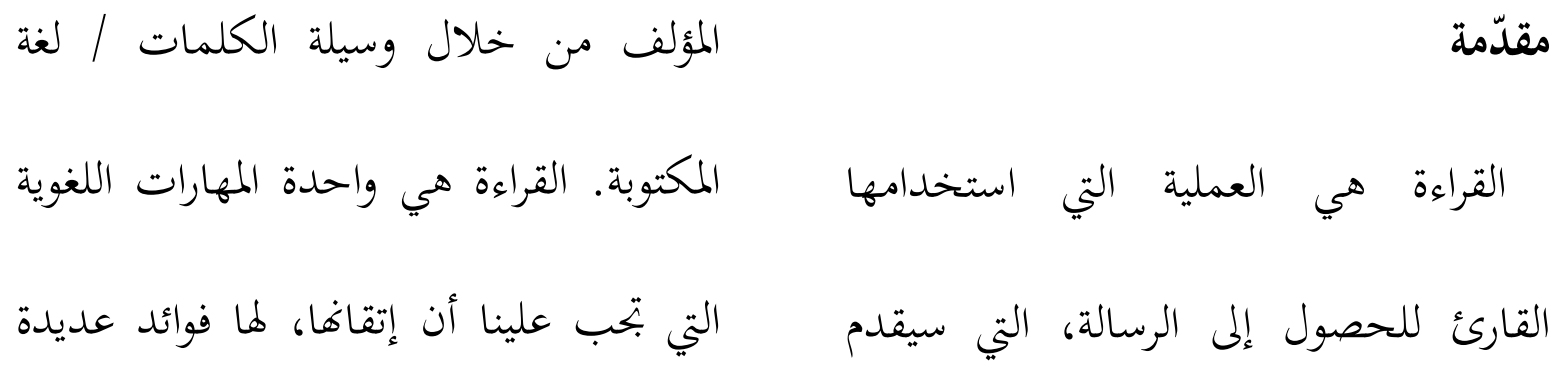


ولكن القراءة هي عملية معقدة. المعقدة

بمعنى عملية القراءة فيها العوامل الداخلية

والعوامل الخارجية القارئ. قد تكون العوامل

الداخلية للاستخبارات، والرغبة، و والموقف،

الموهبة، والدافع، والغرض من القراءة، وغير

ذالك. العوامل الخارجية من وسائل القراءة،

النص، والعوامل المعلم، والعوامل البيئية أو

العوامل الخلفية الاجتماعية والاقتصادية،

$$
\text { والعادة، وتقاليد القراءة. ' ( ) }
$$

بحيث تكون التلاميذ لديهم مهارة القراءة

الجيدة فالعوامل التي تؤثر عليها. فمثال عامل

المعلم. لأن المعلم هو مفتاح التعليم. والمهم في

توفير التعليم في المدارس. فلذلك، تحسين

نوعية التعليم بتحسين نوعية المعلمين. تحسين

1 Nurhadi. 2004. Membaca Cepat Dan Efektif.

Bandung : Sinar Baru, hal. 13
في تطوير لغة التلاميذ. القراءة هي عملية التي تجب علينا أن يثقفها وثقافة القراءة هي تعلم القراءة العربية. لأن اللغة العربية هي واحدة من المدات التي مهمة عند التعليم في إندونيسيا.

في بجال التعليم، ولاسيما اللغة، القراءة هي واحدة من المهارات اللغوية التى تجب على التلاميذ ليحقيقها في التعليم. وتطلب من التلاميذ إتقان القدرة على القراءة، حتى تمكن التلاميذ قادرون على فهم الرسائل والمحتوى تسليمها في اللغة المكتوبة. مهارة القراءة لها جانبين هما القدرة على تغيير شعار الكتابة إلى صوت ويفهم دعنى الوضع كله. بالقراءة تمكن التلاميذ تنال العلوم كثيرة. 
جودة المعلم ليس من حيث الرفاه فقط، الرغبة هي أحد العوامل التي يمكن أن تؤثر ولكن أيضا المهنية، كما المكتوب في دستور على جهد الشخص. واهتمام قوي يسبب ع ا لسنة ه... في الآية (1) (1). كما الجهد الدؤوب، وخطيرة، وليس من السهل ينبغي أن يكون المعلم المهنية كافية كفاءة أن اليأس في مواجهة التحديات. المعلمين. واحد هو الكفاءة المهنية. الكفاءة وتطور الرغبة في التعلم لا تنمو من دون المهنية هي المعلم الذي لها القدرة على المواد دعم من العوامل الزناد التي يمكن أن تؤثر التعليمية على نطاق واسع وعميق من أن على ضمير التلاميذ. العوامل التي تتسبب يسمح توجيه المتعلمين تحقيق الأهداف بمكن أن تسهم في تطوير رغبة التلاميذ هي التعليمية. عامل الكفاءة المهنية للمعلمين، في هذه والعوامل الداخلية أيضا لا تنبغي أن تمر الحالة المعلم أن يحاول إثارة الرغية الطلاب مرور الكرام بسبب العوامل الداخلية هي لإتقان المعرفة من أجل تحقيق الأداء العوامل التي تنشأ من داخل التلاميذ، واحدة المطلوب، مثل مهارات القراءة. منها الرغبة لأن الرغبة هي موضوع الميل إذا كان المعلم لديه الكفاءة المهنية المستمر ليشعر لجذب مجال الدراسة أو حتى يتمكن من زيادة رغبة التلاميذ في موضوع محدد وأعرب عن سروره لتعلم المادة. التعليم بجيث عملية التعليم أكثر فعالية ويكنن 


\section{الإطار النظري}

\section{الكفاءة المهنية لمعلم}

في معيار الوطني للتعليم، توضيح من المادة

^ ب الفقرة (r) ذكرت البند ج أن تعريف

الكفاءة المهنية هي قدرة السيطرة على المواد

التعليمية على نطاق واسع وعميق من أن

يسمح المتعلمين توجيه لتلبية معايير الكفاءة

المحددة في المعايير التعليم الوطني.؟ralyasa)

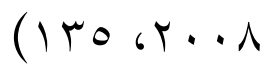

الكفاءة المهنية لمعلم هي قدرة السيطرة

على موضوع واسعة وعميقة، فضلا عن طرق

التدريس وتقنيات وفقا لذلك، مفهومة من

قبل التلاميذ، واشتعلت بسهولة، لا تثير

$$
\text { الصعوبات والشكوك. }
$$

${ }^{2}$ Mulyasa. 2008. Standar Kompetensi dan Sertifikasi Guru. Bandung : PT. Remaja Rosdakarya, hal.135
تحسين التحصيل المعلم لتلاميذ واحد منهم،

ومهارة القرأة لديهم. وفيما يتعلق المدرسة

العالية الإسلامية المهاجرين، وهذه المدرسة

هي مدرسة خاصة التي لديها مرافق الأكثر

واكتمالا، الوالد معاير اكتمالالحاد الأدلن

بجميع المدارس الخاصة في موسي (KKM)

رواس، ومعظم معلم اللغة العربية والتلاميذ

أكثر من غيرها. لذلك الباحثة المهتمة في

دراسة الكفاءة المهنية لمعلم، ورغبة التلاميذ في

تعلم اللغة العربية، ومهارة قراءة النص العربية

بالمدرسة العالية الإسلامية المهاجرين موسي

رواس. ذلك هو العلاقة بين الكفاءة المهنية

لمعلم ورغبة التلاميذ في تعلم اللغة العربية

بكهارة قراءة النص العربية بالمدرسة العالية

الإسلامية المهاجرين موسي رواس. 
لغة أجنبية هي عمل صعب و ممل. لذالك

تحتاج الم الغيرة و الرغبة القوة في إتباع عملية لتحقيق نجاح التعليم.

مؤشرات الرغبة هم الشعور بالسعادة،

مبالاة التلاميذ، اهتمام التلاميذ، مشاركة

$$
\text { التلاميذء }
$$

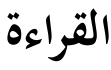

القراءة هي عملية نشطة من العقل الذي

يتم من خلال عيون من القراءة. و يعرف

أيض القراءة و القدرة علي إدراك وفهم

محتويات شيء مكتوب (رمز - شعار

مكتوب)، أو هضمه في القلب.

مؤشر مهارة القراءة من تعلم اللغة العربية

في المدرسة العالية الإسلامية المهاجرين موسي

${ }^{4}$ Safari. 2003 Indikator Minat Belajar. Jakarta :

Rineka Cipta, hal. 13
مؤشرات الكفاءة المهنية للمعلمين هم

إتقان المواد وهيكل ومفهوم وعقلية عملية

تدعم الدرس، إتقان معايير الكفاءة و

الكفاءات الأساسية الدرس، تطوير المواد

التعليم خلاق، تطوير الاحتراف بطريقة

مستدمة من خلال الخاذ إجراءات عاكسة،

واستخدام تكنولوجيا المعلومات والاتصالات

الرغبة

الرغبة هي غيرة قوية لأعمال النشاط

وعملها الشخص بسرور دون إكاره. أن

الرغبة عوامل مهمة في عملية التعليم, خاصة

في دراسة اللغة العربية, لأهما لغة أجنبية. تعلم

${ }^{3}$ Rusman. 2011. Model-model Pembelajaran

Mengembangkan Profesionalisme Guru.

Jakarta : Raja Grafindo, hal. 58

العلاقة بين الكفاءة المهنية لمعلم و رغبة التلاميذ في تعلم اللغة العربية بمهارة قراءة النص العببية بالمدرسة العالية المهاجرين موس رواس سومطرى الجنوبية 
رواس غير التلاميذ قادرين على قراءة النص التي غير تسليم مباشرة إلى العينة. كالتوثيق و

صحيحا، لهجة صحيحة، فهم التركيب ( ) (أرسف

طروق جمع بيانات الآتيات، الإستبيان هي

$(r \cdot) \Lambda-r \cdot) V: R P P$

الطريقة الرئيسي المستخدم للحصول على

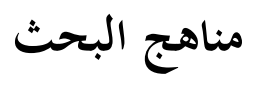

متغيرات البيانات الكفاءة المهنية للمعلمين

تبحث الباحثة بمدخل الكمي مع دراسة

ورغبة التلاميذ. والإختبار لمعرفة مهارة قراءة

العلاقة، العينة ع. • ا تلميذ. ومع ذلك، لأن

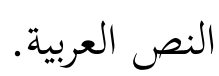

هؤلاء المجتمع متجانسة وطبقية يتناسب،

نتائج البحث

استخدم الباحثة تقنية مجتمع الفصول

الكفاءة المهنية لمعلم اللغة العرابية بالمدرسة

Proporsionate Stratified Random

Sampling

العالية المهاجرين موسي رواس

البيانات الأساسية في هذا البحث هي

السؤال من الإستبيان أربع عشرة سؤالا. و

الكفاءة المهنية لمعلم اللغة العربية، ورغبة

$$
\text { في كل سؤال أن تكون تفصيلا. جواب }
$$

التلاميذ، ومهارة قراءة نص التلاميذ بالمدرسة

Selalu (4)‘sering (3)‘ Kadang-kadang (2)،

العالية المهاجرين موسي رواس. ومصادرها tidak pernah (1)

هي التلاميذ المدرسة العالية المهاجرين موس رواس. حين أن بيانات الثانوي هي البيانات 


\begin{tabular}{|c|c|c|c|c|c|c|}
\hline ف.ك׳' & $r_{5}$ & 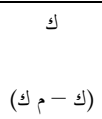 & ف.ك & ف & 5) & رقم \\
\hline$r M \Lambda$ & $1 \leqslant \varepsilon$ & Ir & 114 & $r$ & 07 & 1 \\
\hline$r .$. & $1 \ldots$ & 1. & 1.1 & r & $0 \leqslant$ & $r$ \\
\hline 11 & $\wedge 1$ & 9 & or & 1 & or & $r$ \\
\hline 195 & $7 \varepsilon$ & $\lambda$ & 107 & $r$ & or & $\varepsilon$ \\
\hline $1 \leqslant V$ & $\varepsilon 9$ & v & 10r & $r$ & 01 & . \\
\hline 1.1 & $r y$ & 7 & 10. & $r$ & 0 . & 7 \\
\hline 10 & ro & 。 & rq\& & 7 & $\leqslant 9$ & v \\
\hline 17. & 17 & $\varepsilon$ & $\varepsilon \wedge$. & 1. & \&ᄉ & $\wedge$ \\
\hline 9. & 9 & $r$ & $\varepsilon v$. & 1. & $\varepsilon v$ & 9 \\
\hline$r \varepsilon$ & $\varepsilon$ & r & rVT & 7 & $\leqslant 7$ & 1. \\
\hline 7 & 1 & 1 & rV. & 7 & $\leqslant 0$ & 11 \\
\hline . & . & . & ror & $\wedge$ & $\leqslant \varepsilon$ & IT \\
\hline 。 & 1 & $1-$ & rio & . & $\varepsilon r$ & IT \\
\hline$\varepsilon$. & $\varepsilon$ & $r-$ & $\varepsilon r$. & 1. & $\leqslant r$ & $1 \varepsilon$ \\
\hline$r$ & 9 & $r-$ & $17 \varepsilon$ & $\varepsilon$ & \&1 & 10 \\
\hline 17. & 17 & $\varepsilon-$ & $\varepsilon \ldots$ & 1. & $\varepsilon$. & 17 \\
\hline$r .$. & ro & $0-$ & 107 & $\varepsilon$ & rq & iv \\
\hline $1 \wedge$ & $r y$ & $7-$ & 19. & 。 & $r_{\Lambda}$ & 11 \\
\hline$\varepsilon 9$ & $\varepsilon q$ & $\mathrm{~V}-$ & rv & 1 & $r v$ & 19 \\
\hline IrA & $7 \varepsilon$ & $\Lambda-$ & $r 4$ & $r$ & $r 9$ & $r$. \\
\hline $1 \ldots$ & $1 \ldots$ & $1 .-$ & $r \varepsilon$ & 1 & $r \varepsilon$ & $r$ \\
\hline$|r|$ & $|r|$ & $11-$ & $r r$ & 1 & rT & TY \\
\hline 197 & 197 & $1 \leqslant-$ & $r$. & 1 & $r$. & $r r$ \\
\hline r'74I & & & £019 & $1 . \varepsilon$ & & \\
\hline
\end{tabular}

الجمدول

نتائج الإستبينات عن الكفاءة المهنية لمعلم اللغة العرابية بالمدرسة العالية المهاجرين

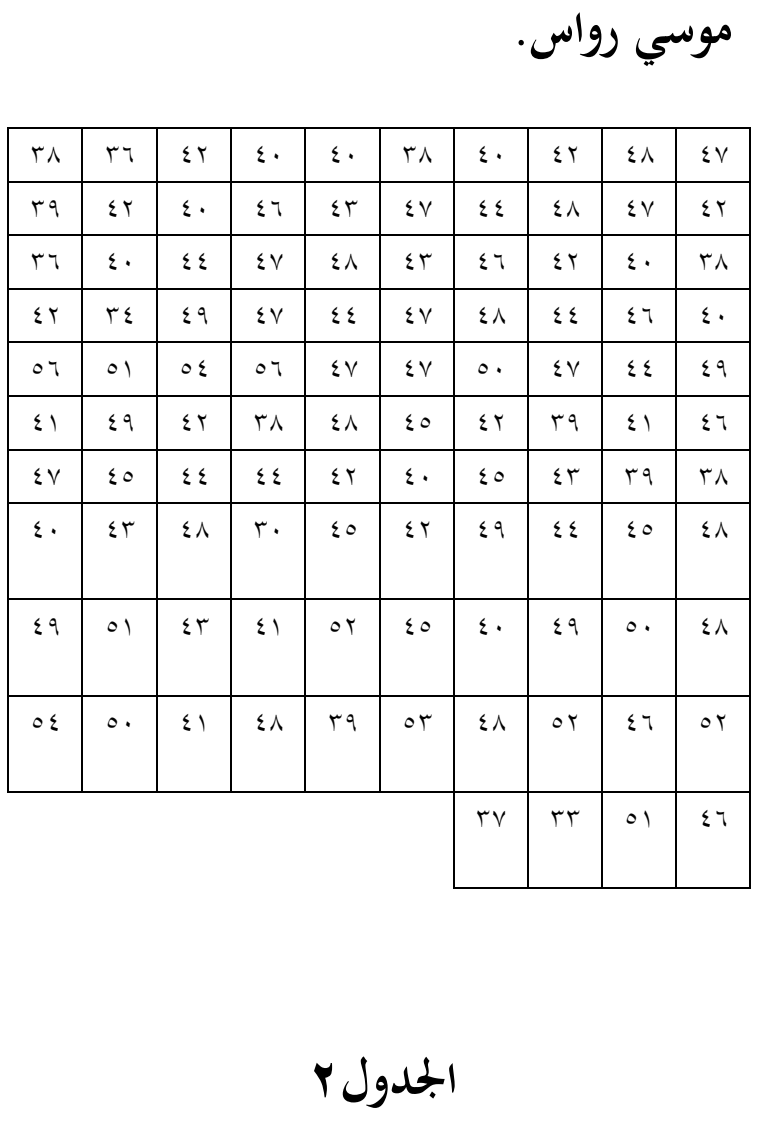

نتائج الكفاءة المهنية لمعلم اللغة العرابية على التوازع المترددات 
المنخفضة (TSR) بإستعمال رموز الآتي ، وهي

$$
\begin{aligned}
& \text { : } \\
& \text { مرتفعة = } \\
& 0.1+\varepsilon \varepsilon= \\
& \text { 9 = } \\
& \text { متوسطة = م - 1.ع إلى م + } 1 . \\
& \varepsilon
\end{aligned}
$$

$$
\text { بين q ج إلى جم = }
$$$$
\text { منخفضة }
$$$$
0.1-\varepsilon \varepsilon=
$$

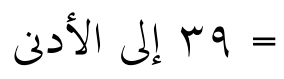

فنعرف أن نتيجة الكفاءة المهنية لمعلم اللغة

العرابية بالمدرسة العالية موسي رواس، أما في

إشارة مرتفعة وهي · r تلاميذا (1\% (1)، و أما في إشارة متوسطة 97 تلاميذا (\% (7)، وأما في إشارة منخفضة 10 .$(\% \backslash 0)$
ومن الجدول السابق، فتستطيع أن تبحث

الباحثة نتيجة معدلة كما يلي :

$$
\frac{53}{j}=
$$

وبالتالى ستبحث الباحثة نتيجة

إخراف المعيارى بإستعمال مربع الاتى ليع لئس :
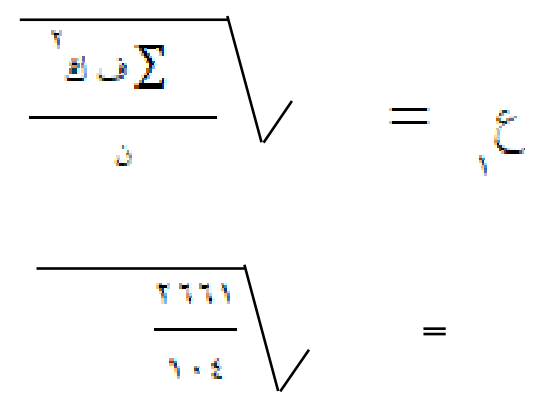

وبعد إيجاد نتجة معدلة (م)عـ ونتيجة الانحراف المعياري (ع)ه ، فخطوة بعدها هي إقرار إلى علامة مرتفعة و المتوسطة و 
الجدول

نتائج رغبة التلاميذ والتوازع المترددات

\begin{tabular}{|c|c|c|c|c|c|c|}
\hline ف.ك׳' & ros & 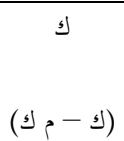 & ف.ك & ف & 5) & رقم \\
\hline$r \leqslant r$ & $|r|$ & 11 & $\wedge \wedge$ & r & $\varepsilon \varepsilon$ & 1 \\
\hline 197 & $\leqslant q$ & V & 17 & $\varepsilon$ & $\varepsilon$. & $r$ \\
\hline YIT & r & 7 & $r r \varepsilon$ & 7 & rq & $r$ \\
\hline$r \ldots$ & ro & 。 & $r \cdot \varepsilon$ & $\wedge$ & rᄉ & $\varepsilon$ \\
\hline 195 & 17 & $\varepsilon$ & $\varepsilon \varepsilon \varepsilon$ & Ir & $r v$ & 0 \\
\hline $0 \leqslant$ & 9 & $r$ & $r 17$ & 7 & דr & 7 \\
\hline$r \wedge$ & $\varepsilon$ & $r$ & $r \leqslant 0$ & $\mathrm{v}$ & ro & $\mathrm{V}$ \\
\hline$\wedge$ & 1 & 1 & TVY & $\wedge$ & $r \varepsilon$ & $\wedge$ \\
\hline . & . & . & rr & v & r & 9 \\
\hline v & 1 & 1 & $T Y \varepsilon$ & v & r & 1. \\
\hline$T \varepsilon$ & $\varepsilon$ & $r-$ & 117 & 7 & ו & 11 \\
\hline 11 & 9 & $r-$ & rV. & 9 & r. & Ir \\
\hline$\varepsilon \lambda$ & 17 & $\varepsilon-$ & $\Lambda V$ & $r$ & rq & $1 r$ \\
\hline 10. & ro & $0-$ & 171 & 7 & $r_{\Lambda}$ & $1 \varepsilon$ \\
\hline $1 \cdot 1$ & r & $7-$ & 11 & $r$ & TV & 10 \\
\hline 91 & $\leqslant 9$ & $V-$ & or & $r$ & TY & 17 \\
\hline roT & $T \leq$ & ᄉ- & $1 \ldots$ & $\varepsilon$ & ro & IV \\
\hline 11 & 11 & $9-$ & $r \varepsilon$ & 1 & $r \varepsilon$ & 11 \\
\hline
\end{tabular}

رغبة التلاميذ بالمدرسة العالية المهاجرين موسي رواس :

السؤال من الإستبيان ثلاث عشرة سؤالا.

و في كل سؤال أن تكون تفصيلا جوابا.

Selalu (4)‘sering (3)، Kadang-kadang (2)، tidak pernah (1)

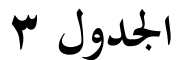

نتائج الإستبينات عن رغبة التلاميذ بالمدرسة العالية المهاجرين موسي رواس

\begin{tabular}{|c|c|c|c|c|c|c|c|c|c|}
\hline r & rr & $r$. & $r_{1}$ & ro & ro & rᄉ & rr & rv & rv \\
\hline TV & $r v$ & r & $\varepsilon \varepsilon$ & ro & $r_{1}$ & $r v$ & ד & $r_{\Lambda}$ & $\iota_{\curlywedge}$ \\
\hline$r \varepsilon$ & $T \varepsilon$ & $r_{1}$ & $r v$ & $\varepsilon$. & $\varepsilon \varepsilon$ & $r \varepsilon$ & r & $r \varepsilon$ & rr \\
\hline YY & $r_{1}$ & $r_{\Lambda}$ & $\varepsilon$. & rq & rv & r & $r_{\Lambda}$ & rv & $r$. \\
\hline rq & $r v$ & rq & rq & ro & $\varepsilon$. & ro & rv & rr & rᄉ \\
\hline$r q$ & ro & ґᄉ & ro & די & rq & ro & $r \varepsilon$ & r & r. \\
\hline$r V$ & $r \varepsilon$ & $r_{\Lambda}$ & $r_{1}$ & $r \varepsilon$ & ro & r & $r$. & $r$. & $r$. \\
\hline$r_{1}$ & rv & $r V$ & rr & $r \varepsilon$ & rT & rᄉ & דr & rr & r \\
\hline$r \wedge$ & Tr & $r v$ & $r q$ & ד & $r v$ & $r_{\Lambda}$ & $r$. & $r q$ & ד \\
\hline rq & rr & $r_{\Lambda}$ & $\varepsilon$. & ro & ro & $r$. & ד & $r \wedge$ & $r_{\Lambda}$ \\
\hline & & & & & & ד & $r \varepsilon$ & $r$. & rr \\
\hline
\end{tabular}


Jurnal Al Bayan Vol.10, No.1, Bulan Juni 2018.ISSN 2086-9282. e-ISSN 2549-1229

وبعد إيجاد نتجة معدلة (م) سب ونتيجة

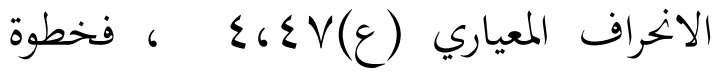
بعلها هي إقرار إلى علامة مرتفعة و المتوسطة و المنخفضة (TSR) بإستعمال رموز الآتي،

:وهي

$$
\text { مرتفعة }
$$

$$
\begin{aligned}
& \varepsilon 6 \varepsilon V .1+\mu r=
\end{aligned}
$$

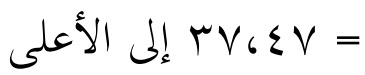

$$
\begin{aligned}
& \text { متوسطة = } \\
& \text { YN60rg rV6\&V بين = } \\
& \text { منخفضة = } \\
& \varepsilon 6 \Omega .1-\mu r=
\end{aligned}
$$

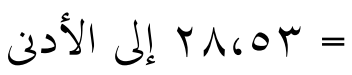

فنعرف أن نتيجة رغبة التلاميذالمدرسة العالية موسي رواس، أما في إشارة مرتفعة وهي بr تلاميذا (\% اب)، و أما في إشارة

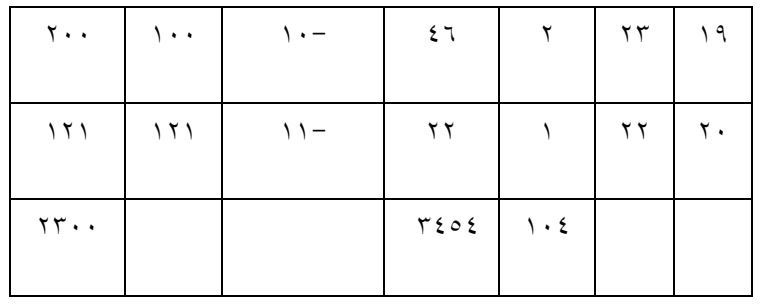

ومن الجدول السابق، فتستطيع أن تبحث

الباحثة نتيجة معدلة كما يلي :

$$
\begin{aligned}
& \frac{3-2 \Sigma}{3}= \\
& \mu=\frac{T \& \delta \varepsilon}{1+\varepsilon}=
\end{aligned}
$$

وبالتالى ستبحث الباحثة نتيجة

إخراف المعيارى بإستعمال مربع الاتى
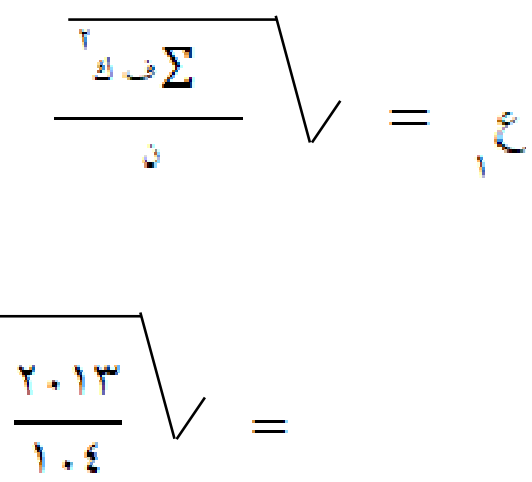

العلاقة بين الكفاءة المهنية لمعلم و رغبة التلاميذ في تعلم اللغة العبية بههارة قراءة النص العربية بالمدرسة العالية المهاجرين موس رواس سومطرى الجنوبية

148 
الجدول I

نتائج مهارة قراءة التلاميذ على التوازع المترددات

\begin{tabular}{|c|c|c|c|c|c|c|}
\hline ف.كs' & 'rs & $\begin{array}{l}\text { s) } \\
\text { s) } \\
\text { (5) }\end{array}$ & ف.ك & ف & 5) & رقم \\
\hline 4177 & ri & 19 & 01. & 7 & 10 & 1 \\
\hline ०^ᄉ & 197 & $1 \varepsilon$ & r $\varepsilon$. & $r$ & $\Lambda$. & r \\
\hline VYq & $\wedge 1$ & 9 & $7 \vee 0$ & 9 & Vo & r \\
\hline rr. & 17 & $\varepsilon$ & $1 \varepsilon \ldots$ & $r$. & $V$. & $\varepsilon$ \\
\hline rr & 1 & $1-$ & $Y \mid \leqslant 0$ & r & 70 & 0 \\
\hline 1111 & r & $7-$ & 191. & r & 7. & 7 \\
\hline $0 . T \leqslant$ & & & 790. & $\begin{array}{l}=ن \\
1 \cdot \varepsilon\end{array}$ & & \\
\hline
\end{tabular}

ومن الجدول السابق، فتستطيع أن

تبحث الباحثة نتيجة معدلة كما يلي :
متوسطة سه تلاميذا (01\%)، وأما في إشارة منخفضة 9 1 تلميذا (1) (1). مهارة قراءة التلاميذ بالمدرسة العالية المهاجرين موسي رواس r. الجحدول

نتائج الإستبينات عن مهارة قراءة التلاميذ المدرسة العالية المهاجرين موسي رواس

\begin{tabular}{|c|c|c|c|c|c|c|c|c|c|}
\hline 70 & 7. & 10 & v. & $\wedge$. & 7. & v. & 7. & 70 & 70 \\
\hline V. & 7. & vo & 10 & 70 & 70 & $v$. & 70 & V. & $v$. \\
\hline 70 & V. & 7. & 10 & 7. & V. & 70 & $v$. & 7. & 7. \\
\hline 70 & 10 & $v$. & 10 & 7. & 70 & 70 & $v_{0}$ & 70 & 70 \\
\hline 70 & 7. & 7. & $\wedge$. & 7. & 70 & 7. & vo & V. & 70 \\
\hline 7. & 70 & 7. & 70 & Vo & V. & 7. & v. & Vo & 7. \\
\hline 70 & 7. & $v$. & 70 & 70 & 70 & 7. & $v$. & 70 & $v$. \\
\hline 7. & 7. & 7. & $v$. & 7. & 70 & 7. & 70 & $v$. & $v_{0}$ \\
\hline V. & 7. & $V_{0}$ & 70 & 70 & V. & 70 & 70 & 70 & 70 \\
\hline Vo & 7. & 7. & $\wedge$. & 7. & 70 & vo & 7. & 70 & 7. \\
\hline & & & & & & 10 & 7. & 7. & 7. \\
\hline
\end{tabular}



$=7690.1+776 \wedge Y 7=$
VY GVVT
متوسطة =
$\varepsilon$
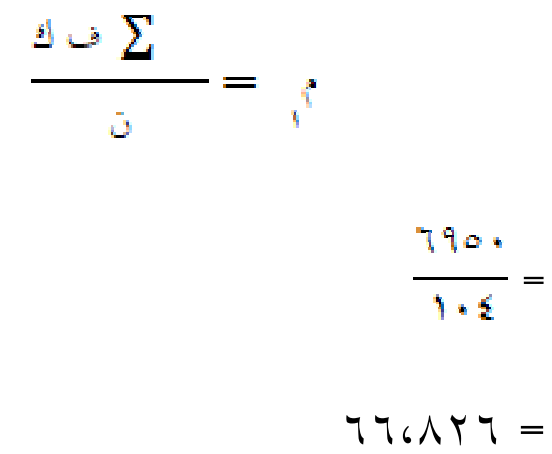

$69 V 7$ g VY 6VVT بين =

09

منخفضة

$=7690.1-7761 T_{7}=$

فنعرف أن نتيجة مهارة

7.

القراءة التلاميذالمدرسة العالية موسي

رواس، أما في إثارة مرتفعة وهي 11

تلميذا (1 V\%)، و و أما في إشارة

متوسطة ماه تلاميذا (1\%) وأما

في إشارة منخفضة تلاميذا سم

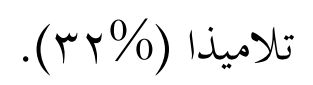

وبالتالى تبحث الباحثة نتيجة إخراف

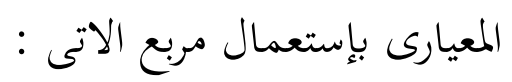
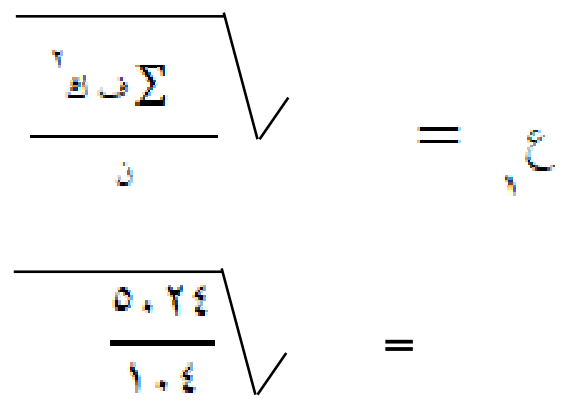

$7690=$

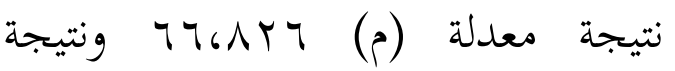

الانحراف المعياري (ع) 760 ، فخطوة بعدها هي إقرار إلى علامة مرتفعة و المتوسطة و المنخفضة (TSR) بإستعمال رموز الآتي،

$$
\text { وهي : مرتفعة : }
$$


عرفنا المعنى ه \% أو $1 \%$ و و بعبارة أخرى

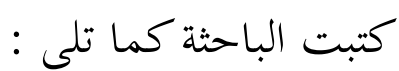

$$
(\cdot 6 r \circ \leq \geq \leq ., V \leq .619)
$$

ولأن "رك ي" أكبر من "ر"تابيل، فإن فرضية

Ho مرفوضة وتقبل Ha يعني وجود علاقة ارتباط قوية بين المتغيركوالمتغير . ي. لذلك ملاحظة أن النتائج التي تم الحصول عليها هي

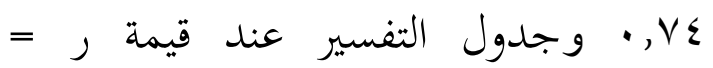
. المتغيرينكويلهم العلاقة قوية أو عالية. لذلك، استنتاج أهما العلاقة بين الكفاءة المهنية لمعلم و رغبة التلاميذ في تعلم اللغة العرابية بههارة قراءةالنصوص العرابية بلمدرسة العالية المهاجرين موسي رواس قوية أو عالية.

\section{خلاصة}

أن الكفاءة المهنية لمعلم اللغة العربية بالمدرسة العالية المهاجرين موسي رواس في إشارة متوسطة بنتيجة معدلة يعن 79 (ד־\%). أن رغبة التلاميذ في تعلم اللغة العربية في المدرسة العالية المهاجرين موسي الفي لفي الفيه
العلاقة بين الكفاءة المهنية لمعلم و رغبة التلاميذ في تعلم اللغة العربية بمهارة قراءة النص العربية بالمدرسة العالية المهاجرين

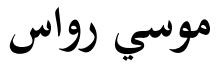
$R_{y, x_{1} x_{2}}=\sqrt{\frac{r_{y x_{1}}{ }^{2}+r_{y x x_{3}}{ }^{2}-2 r_{y x_{x}} r_{y x_{2}} x_{x_{2} x_{3}}}{1-r_{x_{1} x_{2}}{ }^{2}}}$

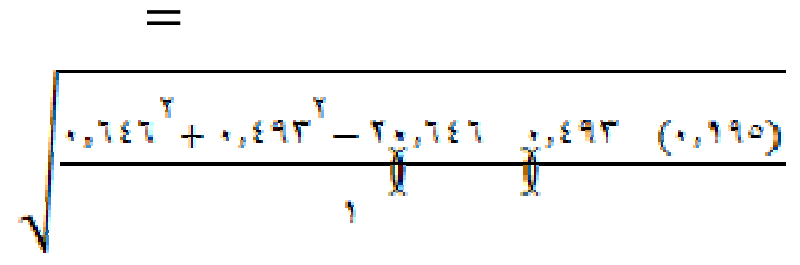

$$
=\cdot, \vee \varepsilon
$$

بعد الحصول على نتيجة من "رك ا ك كب

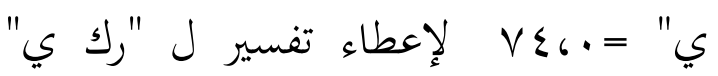
وبالتالي نرى السعر "ر" بإستعمال رموز

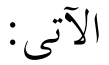

$$
\text { ن د }
$$

$$
1 \cdot 1=r-1 \cdot \varepsilon=
$$

بحد الباحثة "دف" = 1 ـ (وفيها بحد الباحثة

قيمة دف= 1901، ـ فن طرف المعنى ه \%

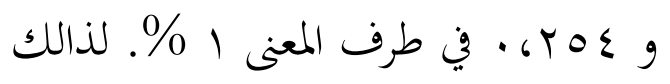


رحال بن بطوطة. مفهوم القراءة و تطويره. rᄉ www.kasba.ibda.org

$$
r \cdot I_{1 V}
$$

الشيخ مصطفى الغلاييني. 1990 1. جهود معلم على رغبة التلاميذ. بيروت:

$$
\text { المكتبة العصيرة }
$$

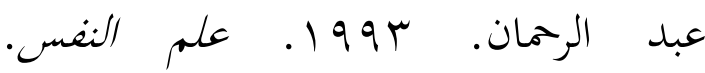
جوكجاكرتا: تيارجان

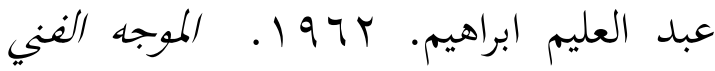

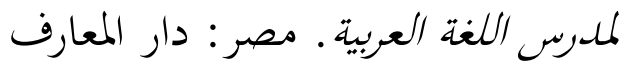
عمر عبد حسنة. مهارة التربية الإسلامية. المكتبة الإسلامية. التاريخ ب إنبراير

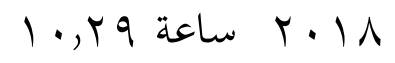

محمد مكرم بن منظور اللسان العرب. r...

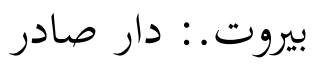

محمود يونس. 199. قموس عربي اندونيسي. جاكرتا : هيدا أكونج منور. ع99 19. قاموس المنور الغربية. جوكجاكرتا: معهد المنور مؤمن زين العارفين. • .99 1 ـ المستخالص في

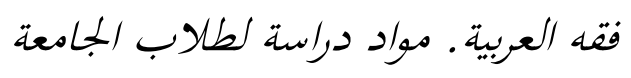

رواس في إشارة متوسطة بنتيجة معدلة يعني rه (1\%). أن مهارة قراءة النص العربية في المدرسة العالية المهاجرين موسي رواس في إشارة متوسطة بنتيجة معدلة يعني مابك (1\%) برغبة التلاميذ في تعلم اللغة العربية بمهارة قراءة النص بالمدرسة العالية المهاجرين موسي

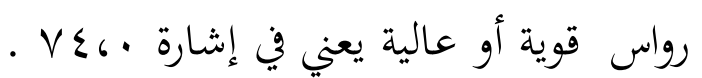

\section{مراجع الكتابة}

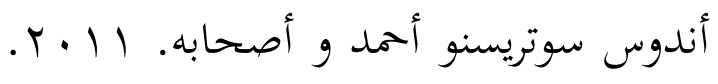

أصول التربية والثعليم الجزء الثالث.

فونوركو : معهد دار السلام كنتور

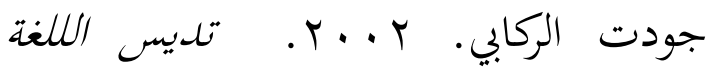

العربية. سورية : دار الفكر

خطابية ماجد. ץ. ب. r. التربية العملية الأسس النظرية و تنبيقاتها. عمان.

$$
\text { الأردان : دار الشروق }
$$

دكتورتونس محمد سالفين. 1997 ـ ـ علم اللغة العام. رياض: دار المسلم للنشر والنوريح 
Mulyasa. 2008. Standar Kompetensi dan Sertifikasi Guru. Bandung : PT. Remaja Rosdakarya

Nurhadi. 2004. membaca cepat dan efektif. Bandung : Sinar Baru.

Nurtanto, Muhammad. 2018. Mengembangkan Kompetensi Profesionalisme Guru Dalam Menyiapkan Pembelajaran Yang Bermutu. Serang:UNTIRTA. jurnal.fkip.uns.ac.id diakse pada 03 Maret 2018 23.05 WIB

Pujasari, Yayah dan Nurdin. 2018. Pengaruh Kompetensi Profesional Guru Terhadap Keberhasilan Belajar Siswa. Bandung : UPI. ejournal.upi.edu diakses pada 03 Maret 201820.02 WIB

Roskina Mas, Sitti. 2012. Hubungan Kompetensi Personal dan Profesional Guru dengan Motivasi Belajar Siswa di SMKN 2 Kota Gorontalo. Gorontalo: Fakultas Sastra dan Budaya Universitas Negeri Gorontalo. vol 19 no 2 (journal.um.ac.id diakses pada 04 Maret 2018 19.36)

RPP Pembelajaran Bahasa Arab kelas XI tahun ajaran 2017-2018

Rusman. 2011. Model-model Pembelajaran Mengembangkan Profesionalisme Guru. Jakarta : Raja Grafindo

Rusman. 2011. Model-model Pembelajaran Mengembangkan Profesionalisme Guru. Jakarta : Raja Grafindo

Safari. 2003 Indikator Minat Belajar. Jakarta : Rineka Cipta.

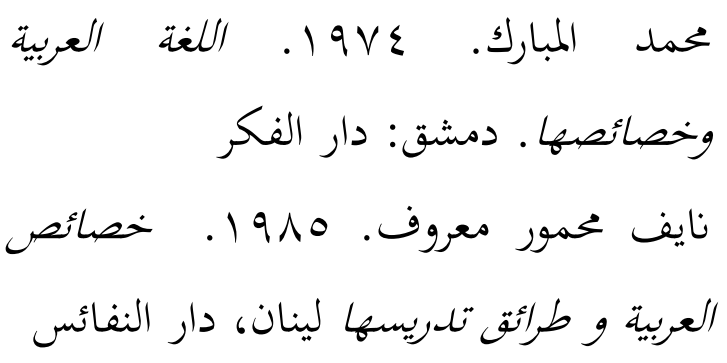

Abidin, Yunus. 2012. Pembelajaran Membaca Berbasis Pendidikan Karakter. Bandung: PT Refika Aditama

Arikunto, Suharsimi. 2006. Prosedur Penelitian Suatu Pendekatan Praktek. Jakarta : PT Rineka Cipta

Budiwibowo, Satrijo. 2016. Hubungan Minat Belajar Siswa Dengan Hasil Belajar IPS ( Madiun : Gulawentah. Jurnal Studi Sosial. http://ejournal.ikippgrimadiun.ac.id diakses pada 03 Maret 2018 $00.13 \mathrm{WIB}$

Danim, Sudarwan. 2002. Inovasi Pendidikan : Dalam Upaya Peningkatan Profesionalisme Tenaga Kependidikan. Bandung : CV. Pustaka Setia

Fathul, Mujib dan Nailur Rahmawati. 2012. Permainan Edukatif Pendukung Pembelajaran Bahasa Arab. Yogyakarta : Diva Press

Hairani, Makmun. 2017. Psikologi Belajar. Yogyakarta : Aswaja Pressindo

Mudlofir, Ali. 2013. Pendidik Profesional. cet. Ke 2. Jakarta :Raja Grafindo 
skripsi Ninik Zatulani UIN SUKA).
Sagala, Syaiful. 2013. Keтатрuan Profesional Guru dan Tenaga Kependidikan. Bandung : Alfabeta

Slameto. 2015. Belajar dan faktor-faktor yang mempengaruhinya. (Bandung: Remaja Rosdakarya

Sudijono, Anas. 2015. Pengantar Statistik Pendidikan. Jakarta. Rajawali Pers

Sugiyono. 2014. Metode Penelitian Pendidikan Pendekatan Kuantitatif. Kualitatif. $R$ and $D$. Jakarta : Penerbit Alfabeta

Suhaebah, Nur. 2014. Pengaruh Pengelolaan Kelas Terhadap Minat Belajar PKN Pada Peserta Didik Di SMA 1 Polewali. Polewali : Jurnal Pepatuzdu. Vol.8 No.1 journal.lppm-unasman.ac.id diakses pada 03 Maret 201800.34 WIB

Theresia Hery, Maria. 2015. Upaya Meningkatkan Minat Dan Prestasi Belajar Matematika Siswa Dengan Menggunakan Penerapan Pembelajaran Berbasis Multimedia Interaktif. Madiun : Jurnal Ilmiah Edukasi Matematika. Vol.1 no.1 download.portalgaruda.org diakses pada 03 Maret 201800.50 $W I B$

Uzer Usman, Moh. 1998. Menjadi Guru Profesional. Bandung: Remaja Rosdakarya

W.S Winkel. 1996. Psikologi Pendidikan. Jakarta : Grasindo

Yunus, Mahmud. 1983. Metodik Khusus Bahasa Arab. ( Jakarta : Hidakarya Agung (di dalam 